\title{
Nyreskade forårsaket av legemidler
}

\author{
Man bør alltid vurdere legemidler som årsak ved både akutt og kronisk \\ nyreskade. Medikamenter kan forårsake alle former for nyreskade med \\ forskjellige kliniske manifestasjoner og ulik patogenese. Pasientens \\ alder, hydreringsstatus, opprinnelig nyrefunksjon og eventuell atero- \\ sklerose påvirker risikoen for legemiddelrelatert nyreskade.
}

Se også kunnskapsprøve på www.tidsskriftet.no/quiz

\section{Aud Høieggen}

uxaudh@ous-hf.no

Ingrid Os

Nyremedisinsk avdeling

Oslo universitetssykehus, Ullevål

Nyrene er utsatt for medikamentskade av flere årsaker. Konsentrasjonen av legemidler som skilles ut renalt, er høyere i urin enn i plasma ettersom utfiltrert legemiddel oppkonsentreres i nefronets tubulussystem. Aktiv reabsorpsjon og sekresjon øker i tillegg intracellulær konsentrasjon i tubuluscellene. Dette kan gi celleskade. Legemidler kan også påvirke nyregjennomblødningen direkte via hemodynamiske effekter eller indirekte gjennom igangsetting av immunologiske prosesser i nyrene. I tillegg er nyrene sårbare, særlig tubuli pga. den særegne sirkulasjonen med blodforsyning fra vasa recta til deler av nyremargen. Det gjør at oksygentilførselen er marginal samtidig som det er et stort energibehov i forbindelse med ionetransport.

Legemidler kan affisere nyrene prerenalt (hemodynamisk), intrarenalt (immunologisk, toksisk) eller ved obstruksjon av nyretubuli (fig 1). Allmennmedisineren vil oftest se medikamentrelatert nyreskade i forbindelse med hyppig brukte midler mot høyt blodtrykk og hjertesvikt, ikke-steroide antiinflammatoriske midler (NSAID-preparater) og antibiotika. Vi har derfor valgt å vektlegge disse medikamentene.

Data til denne artikkelen er hentet ved et litteratursøk i PubMed og fra databasen UpToDate. Utvalget er skjønnsmessig ut fra forfatternes erfaring innen feltet.

\section{Mekanismer for nyrepåvirkning \\ Hemodynamisk påvirkning}

Autoreguleringen i nyrene gjør at det glomerulære filtrasjonstrykket - og dermed den glomerulære filtrasjonshastigheten - kan opprettholdes til tross for endringer i systemisk blodtrykk. Ved fall i perfusjonstrykket, som ved dehydrering og blodtrykksfall av andre årsaker, vil den tilførende arteriolen dilateres av prostaglandiner og den fraførende arteriolen konstringeres av angiotensin II for å opprettholde glomerulustrykket (fig 1). Hemmere av renin-angiotensin-systemet og prostaglandinsyntesehemmere, som NSAIDpreparater, vil kunne motvirke denne autoreguleringen og påføre fall i glomerulær filtrasjonshastighet. Spesielt utsatt er pasienter med allerede sviktende autoregulering, som ved hypertensjon, høy alder, diabetes, hjertesvikt eller nyresykdom.

\section{Immunologisk og toksisk skade}

Akutt tubulær nekrose er den hyppigste formen for akutt nyreskade i sykehus og kan være iskemisk betinget eller toksisk utløst av legemidler $(1,2)$. Nyreskaden er som oftest reversibel og ikke-oligurisk. Akutt tubulær nekrose er ofte en eksklusjonsdiagnose hvor man må utelukke andre årsaker til akutt nyresvikt som prerenal nyresvikt, akutt glomerulonefritt, vaskulitt eller postrenalt hinder. Grundig sykehistorie med medikamentanamnese, vurdering av pasientens blodtrykk og hydreringstilstand, urinmikroskopi, kvantifisering av proteiner i urin og ultralyd av nyrer og urinveier hører med. Man bør også sikre seg immunologiske og serologiske prøver (ekstraherbare kjerneantistoffer (ENA), antinøytrofile cytoplasmaantistoffer (ANCA) og antistoffer mot glomerulusbasalmembran (anti-GBM), hepatitt B og C og hivantistoff). Den viktigste behandlingen av akutt tubulær nekrose er å seponere medikamenter som man mistenker, og sørge for at pasienten er godt hydrert og at blodtrykket er innenfor normalområdet.

Akutt interstitiell nefritt er en sjeldnere årsak til nyreskade enn akutt tubulær nekrose, og de fleste tilfellene (ca. 70\%) skyldes legemidler (3) (fig 1). Akutt interstitiell nefritt er en hypersensitivitetsreaksjon. Symptomene kan opptre få dager til flere uker etter inntak av medikamentet, og de er ikke doseavhengige. Det er ofte både lavgra- dig proteinuri, hematuri og leukocyturi med eller uten hvite blodcellesylindere. Urinfunnene skiller akutt interstitiell nefritt fra akutt tubulær nekrose, hvor det som oftest verken forekommer hematuri eller proteinuri. Ved akutt tubulær nekrose ses derimot ofte multiple, mørke, tette og kornete sylindere.

Feber, utslett og muskel- og leddsmerter er ofte ledsagende symptomer ved akutt interstitiell nefritt. Tilstanden bedres som oftest 1-2 uker etter seponering av utløsende medikament. Kortikosteroider kan vurderes fordi dette er en allergisk reaksjon, og behandlingen bør helst starte tidlig i forløpet $(4,5)$. Sikker diagnose kan bare stilles ved nyrebiopsi. En sjelden gang kan man se nefrotisk syndrom utløst av legemidler i sammenheng med interstitiell nefritt. Dette skyldes oftest NSAID-preparater (6).

\section{Obstruksjon}

Metotreksat, aciklovir og sulfonamider er eksempler på legemidler som kan forårsake obstruksjon av tubuli med akutt nyresvikt som følge, omtrent som myoglobin ved rabdomyolyse. Medikamentkrystaller felles ut i tubuli, og tubulicellene kan også skades direkte (fig 1). Det er økt risiko for utfelling ved sur urin og ved dehydrering. Som oftest ser man en ikke-oligurisk, reversibel nyresvikt, og pasienten kan ha flankesmerter og funn av røde og hvite blodceller og krystaller i urin (7).

\section{Medikamenter hyppig assosiert med nyreskade Antibiotika}

Antibiotika er ofte relatert til akutt nyreskade fordi de er i utstrakt bruk og kan gi både akutt tubulær nekrose og akutt interstitiell nefritt.

Aminoglykosider er den gruppen antibio-

\section{Hovedbudskap}

- ACE-hemmere og All-antagonister bør forbigående seponeres ved interkurrent sykdom som kan medføre dehydrering

- Bruk av ikke-steroide antiinflammatoriske legemidler bør unngås hos pasienter med nyresykdom, hjertesvikt, hypertensjon og andre tilstander hvor nyrens autoregulering kan være forstyrret

- Metformin bør unngås ved nedsatt nyrefunksjon 


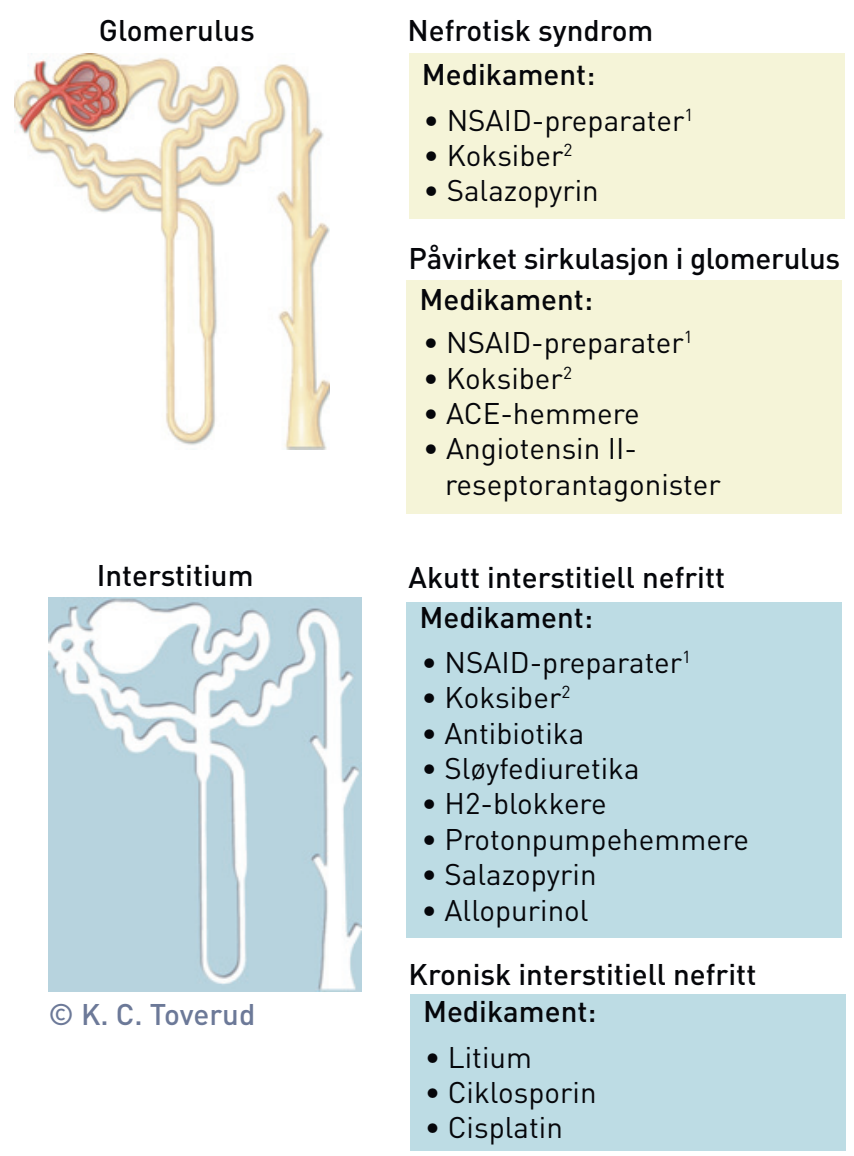

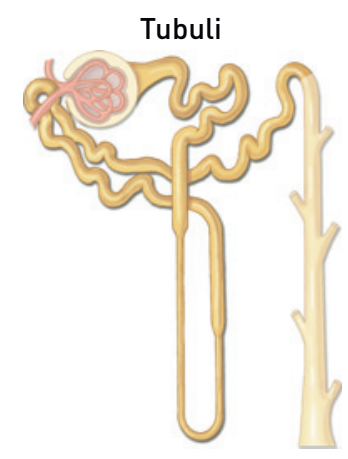

Akutt tubulær nekrose

Medikament:

- Aminoglykosider

- Amfotericin

- Kefalosporiner

- Cisplatin

- Tenofovir

- Andre

Obstruksjon av tubuli

Medikamenter:

- Metotreksat

- Aciklovir

- Sulfonamider

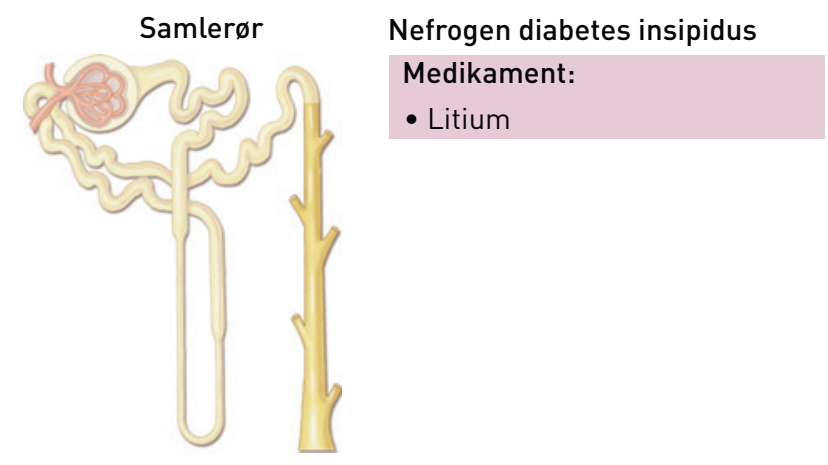

${ }^{1}$ ikke-steroide antiinflammatoriske legemidler ${ }^{2}$ selektive COX-2-hemmere

Figur 1 Hvor og hvordan enkelte legemidler kan påvirke nyrefunksjonen

tika som oftest forårsaker akutt tubulær nekrose. Nyreskade observeres hos $10-20 \%$ av brukerne, særlig gjelder dette neomycin og gentamicin $(8,9)$. Skaden skjer først og fremst i proksimale tubuli der medikamentet reabsorberes etter å ha blitt fritt filtrert i glomeruli. Kreatininstigningen kan vise seg lang tid etter behandling pga. akkumulering av aminoglykosid i proksimale tubuliceller. Man bør derfor kontrollere nyrefunksjonen både én og to uker etter avsluttet behandling. Faktorer som øker risikoen for akutt tubulær nekrose ved bruk av aminoglykosider er langvarig behandling, dehydrering, underliggende nyresykdom, hypokalemi, hypomagnesemi, høy alder og kombinasjon med andre nefrotoksiske medikamenter inkludert røntgenkontrast. Akutt nyreskade kan oppstå selv om plasmakonsentrasjonen av aminoglykosid ligger innenfor referanseområdet (10). Medikamentet må kun brukes på klar indikasjon og seponeres dersom nyreskade oppstår. God hydrering kan motvirke toksisiteten.

\section{Ikke-steroide}

antiinflammatoriske legemidler

Alle NSAID-preparater, inkludert koksiber, kan gi nyreskade. Medikamentene motvirker den prostaglandinmedierte dilatasjonen av tilførende arteriole (fig 1) og bør derfor unngås når prostaglandiner er nødvendig for å opprettholde renal blodgjennomstrøm- ning, som hos nyre- og hjertesviktpasienter. Spesielt uheldig er den hemodynamiske påvirkningen hvis prostaglandinhemmere kombineres med ACE-hemmere og AIIreseptorantagonister. Hos friske mennesker betyr ikke prostaglandiner så mye for blodgjennomstrømning i nyrene (11). NSAIDpreparater er også en hyppig årsak til akutt interstitiell nefritt, og de kan en sjelden gang utløse nefrotisk syndrom.

\section{Litium}

Litium kan føre til renal diabetes insipidus med polyuri. Dette skyldes påvirkning av akvaporiner i samlerørene. Kronisk interstitiell nefritt med irreversibelt gradvis fall $i$ glomerulær filtrasjonshastighet forekommer hos ca. $20 \%$ av pasientene som har fått litium over flere år og kan i verste fall føre til dialysetrengende nyresvikt (12). Forebygging med nøye oppfølging av plasmakonsentrasjonen, som bør ligge lavest mulig, og råd om rikelig væskeinntak er viktig. Seponering av litium bremser skaden, men man må vurdere alvorlighetsgrad av nyreskaden opp mot nytten av behandlingen og om det finnes tilgjengelige alternativer.

\section{Hemmere av renin-angiotensin-systemet}

Ettersom flere pasienter blir eldre og lever lenger med hjerte- og nyresvikt, er ACEhemmere og AII-reseptorblokkere blitt en meget hyppig årsak til akutt nyresvikt. Ef- fekten er hemodynamisk og som oftest reversibel, men nyresvikten kan være så alvorlig at dialyse blir nødvendig. Livstruende hyperkalemi kan forekomme, særlig i kombinasjon med kaliumsparende diuretika og/ eller aldosteronantagonister (13). Angiotensin II er vasokonstringerende primært i glomerulus' fraførende arteriole, og blokkering av vasokonstriksjonen her medfører et fall i glomerulært filtrasjonstrykk. Hos de fleste friske personer er dette knapt registrerbart. Ved marginalisert renal gjennomblødning, som hos pasienter med diabetes, nyresykdom, hypertensjon, hjertesvikt eller nyrearteriestenose, kan man få en signifikant (> 20-25\%) økning i s-kreatinin, og medikamentet må da seponeres eller dosen reduseres. Man skal derfor alltid kontrollere nivået av s-kreatinin og kalium noen dager etter oppstart med renin-angiotensin-hemmere og etter økning av dosen. Mange pasienter vil tåle medisinene godt inntil det systemiske blodtrykket av en eller annen grunn faller, for eksempel ved en gastroenteritt eller dehydrering av andre årsaker. Det er derfor svært viktig at spesielt eldre og pasienter med hjertesvikt informeres om å kontakte lege eller slutte med ACE-hemmere og AIIreseptorblokkere ved interkurrent sykdom.

Det paradoksale med disse medikamentene er at de virker nyrebeskyttende over tid og reduserer proteinuri, slik at nettopp nyresyke har stor nytte av dem. Kombinasjons- 
behandling med ACE-hemmere og AII-antagonister skal sannsynligvis ikke brukes fordi det medfører økt risiko for redusert nyrefunksjon og elektrolyttforstyrrelser (14).

\section{Metformin}

Metformin er ikke direkte nyreskadelig, men kan føre til livstruende laktacidose i forbindelse med akutt nyrefunksjonsnedsettelse. Dette skyldes at metformin akkumuleres ved nedsatt nyrefunksjon og hemmer laktatnedbrytning. I Norge har vi registrert at dette er et økende problem $(15,16)$. Pasienter som bruker metformin for type 2-diabetes må alltid informeres om å ta kontakt med lege eller ta en behandlingspause ved interkurrent sykdom som kan medføre dehydrering. Igjen er dette særlig viktig hos pasienter som samtidig bruker ACE-hemmere eller AII-reseptorblokkere, NSAID-midler eller skal få jodholdig røntgenkontrast. Nyrefunksjonen må alltid sjekkes før man starter med metformin og bør etter vår mening ikke gis ved glomerulær filtrasjonsrate $(\mathrm{GFR})<60 \mathrm{ml} / \mathrm{min} / 1,73 \mathrm{~m}^{2}$.

\section{Konklusjon}

En grundig medikamentanamnese hører alltid med i utredningen av akutt og kronisk nyresykdom. Medikamenter som påvirker renin-angiotensin-systemet kan hos utsatte pasienter forårsake akutt nyreskade, og man må informere pasientene om risikoen og hvilke forholdsregler de bør ta. NSAID-preparater bør om mulig unngås hos pasienter med erkjent nyresykdom, hypertensjon og/ eller hjertesvikt. NSAID-midler og antibiotika er den hyppigste årsaken til medikamentindusert interstitiell nefritt. Metformin har etter vår mening ingen plass i behandlingen av pasienter med glomerulær filtrasjonsrate $(\mathrm{GFR})<60 \mathrm{ml} / \mathrm{min} / 1,73 \mathrm{~m}^{2}$.

\section{Aud Høieggen (f. 1956)}

er spesialist $\mathrm{i}$ indremedisin og nyremedisin, overlege dr.med. ved Nyremedisinsk avdeling, Oslo universitetssykehus, Ullevål. Hun er vikar som førsteamanuensis, Institutt for klinisk medisin, Medisinsk klinikk, Nyremedisinsk avdeling fra 15.4. 2012

Forfatteren har fylt ut ICMJE-skjemaet og oppgir ingen interessekonflikter.

\section{Ingrid Os (f. 1950)}

er spesialist $\mathrm{i}$ indremedisin og nyremedisin, professor dr. med. Fra 1.2. 2012 er hun studiedekan ved Det medisinsk fakultet, Universitetet i Oslo.

Forfatteren har fylt ut ICMJE-skjemaet og oppgir følgende interessekonflikter: Hun har mottatt foredragshonorar fra Abbott, Novartis,

Swedish Orphan, Genzyme og Anger.

\section{Litteratur}

1. Liaño F, Pascual J. Epidemiology of acute renal failure: a prospective, multicenter, communitybased study. Kidney Int 1996; 50: 811-8.

2. Mehta RL, Pascual MT, Soroko S. Spectrum of acute renal failure in the intensive care unit: the PICARD experience. Kidney Int 2004; 66: 1613-21.

3. Rossert J. Drug-induced acute interstitial nephritis. Kidney Int 2001: 60: 804-17.

4. González E, Gutiérrez E, Galeano C et al. Early steroid treatment improves the recovery of renal function in patients with drug-induced acute interstitial nephritis. Kidney Int 2008; 73: 940-6.

5. Clarkson MR, Giblin L, O'Connell FP et al. Acute interstitial nephritis: clinical features and response to corticosteroid therapy. Nephrol Dial Transplant 2004: 19: 2778-83

6. Alper AB Jr, Meleg-Smith S, Krane NK. Nephrotic syndrome and interstitial nephritis associated with celecoxib. Am J Kidney Dis 2002: 40: 1086-90.

7. Sawyer MH, Webb DE, Balow JE et al. Acyclovirinduced renal failure. Clinical course and histology. Am J Med 1988; 84: 1067-71.

8. Humes HD. Aminoglycoside nephrotoxicity. Kidney Int 1988; 33: 900-11.

9. Williams PD, Bennett DB, Gleason CR et al. Correlation between renal membrane binding and nephrotoxicity of aminoglycosides. Antimicrob Agents Chemother 1987; 31: 570-4.

10. Lopez-Novoa JM, Quiros Y, Vicente L et al. New insights into the mechanism of aminoglycoside nephrotoxicity: an integrative point of view. Kidney Int 2011; 79: 33-45.

11. Os I. COX-2 inhibitors and their effects on kidney and blood pressure. Tidsskr Nor Laegeforen 2003; 123: $1339-41$

12. Grandjean EM, Aubry JM. Lithium: updated human knowledge using an evidence-based approach: part III: clinical safety. CNS Drugs 2009; 23 $397-418$

13. Juurlink DN, Mamdani MM, Lee DS et al. Rates of hyperkalemia after publication of the Randomized Aldactone Evaluation Study. N Engl J Med 2004: 351: 543-51.

14. Mann JF, Schmieder RE, McQueen M et al. Renal outcomes with telmisartan, ramipril, or both, in people at high vascular risk (the ONTARGET study): a multicentre, randomised, double-blind, controlled trial. Lancet 2008; 372: 547-53.

15. Gudmundsdottir H, Aksnes H, Heldal K et al. Metformin and antihypertensive therapy with drugs blocking the renin angiotensin system, a cause of concern? Clin Nephrol 2006; 66: 380-5.

16. Gudmundsdottir H, Brørs O, Os I. Metformin should not be used by patients with reduced renal function. Tidsskr Nor Legeforen 2008; 128: 936-7.

Mottatt 8.7. 2011, første revisjon innsendt 30.11. 2011, godkjent 18.4. 2012. Medisinsk redaktør Mette Sagsveen. 